\title{
Editorial: Carbon Storage in Agricultural and Forest Soils
}

\author{
Abad Chabbi ${ }^{1,2}$, Cornelia Rumpel ${ }^{3}$, Frank Hagedorn ${ }^{4}$, Marion Schrumpf $^{5}$ and \\ Philippe C. Baveye ${ }^{6 *}$
}

${ }^{1} I N R A E$, UMR ECOSYS, Bâtiment EGER, Thiverval-Grignon, France, ${ }^{2} I N R A E$, Centre de recherche Nouvelle-Aquitaine-Poitiers, URP3F, Lusignan, France, ${ }^{3} \mathrm{CNRS}$, Institute for Ecology and Environmental Sciences (UMR Sorbonne U, CNRS, IRD, INRA, UPEC), Paris, France, ${ }^{4}$ Swiss Federal Institute for Forest, Snow and Landscape Research (WSL), Birmensdorf, Switzerland, ${ }^{5}$ Max Planck Institute for Biogeochemistry, Jena, Germany, ${ }^{6}$ Saint Loup Research Institute, Saint-Loup-Lamairé, France

Keywords: soil organic matter, greenhouse gas production, soil functions, ecosystem services, climate change

\section{Editorial on the Research Topic}

\section{Carbon Storage in Agricultural and Forest Soils}

Current estimates of global soil $\mathrm{C}$, in both inorganic and organic forms, are slightly over $4,000 \mathrm{Pg} \mathrm{C}$, which is more than five times the amount of carbon currently in the atmosphere or, put differently, is equivalent to about 400 times the amount of $\mathrm{C}$ released yearly to the atmosphere by fossil fuel combustion or cement production. Therefore, even a small drop, of the order of a percent, of the amount of carbon contained in soils, due to a rise in ambient temperature and a resulting stimulation of microbial metabolism, could lead in the long run to a very noticeable increase in atmospheric $\mathrm{C}$ in the long run and a devastatingly positive feedback to climate change. Conversely, a small increase in the amount of carbon held in soils, brought about for example by a shift in agricultural or forest management practices, could, even if it is in some small measure, contribute to climate change mitigation if brought to scale. Moreover, the amount of soil organic matter also influences the architecture of soils, and therefore their ability to transmit and retain water, which has important consequences in terms of mitigating floods, preventing erosion, providing adequate moisture for plants, and recharging aquifers. In addition, soil organic matter represents an important reservoir for nutrients and is thus of central importance for soil fertility and securing food production.

Because of this crucial importance of soil organic matter storage to a range of issues of great concern to human societies, researchers have devoted a significant and rapidly growing amount of attention to the topic over the last 2 decades. Progress has been made in a number of respects, and the consensus is stronger than ever in most parts of the world that soil carbon contents need to be brought back to levels they had several decades ago, before the adoption of industrial agricultural practices. Many difficult questions, however, remain unanswered at this stage and continue to be the object of sometimes intense debates, for example concerning the temperature dependence of the fate and dynamics of soil organic matter in differently managed soils (e.g., Moinet et al., 2019; Moinet et al., 2020; Gutières et al., 2021; Laub et al., 2021), the practical problems that priming may pose to efforts to store more carbon in soils (e.g., Kaštovská et al., 2021; Thilakarathna and HernandezRamirez, 2021), the impact of inorganic carbon compounds on the dynamics of soil carbon storage (e.g., Ferdush and Paul, 2021; Raza et al., 2021), or the relative potential of various agricultural or forest management practices to preserve or even increase carbon stocks in the future (Rumpel et al., 2018; Amelung et al., 2020; Baveye et al.; Baveye, 2021; Gao et al., 2021; Rumpel and Chabbi, 2021; Berthelin et al., 2022).

In this general context, the present Research Topic (RT) was launched with the intent to serve as an outlet for manuscripts that would address one or several of the many interwoven facets of carbon storage in soils. Indeed, SOC sequestration is the result of an array of dynamic biological, chemical 


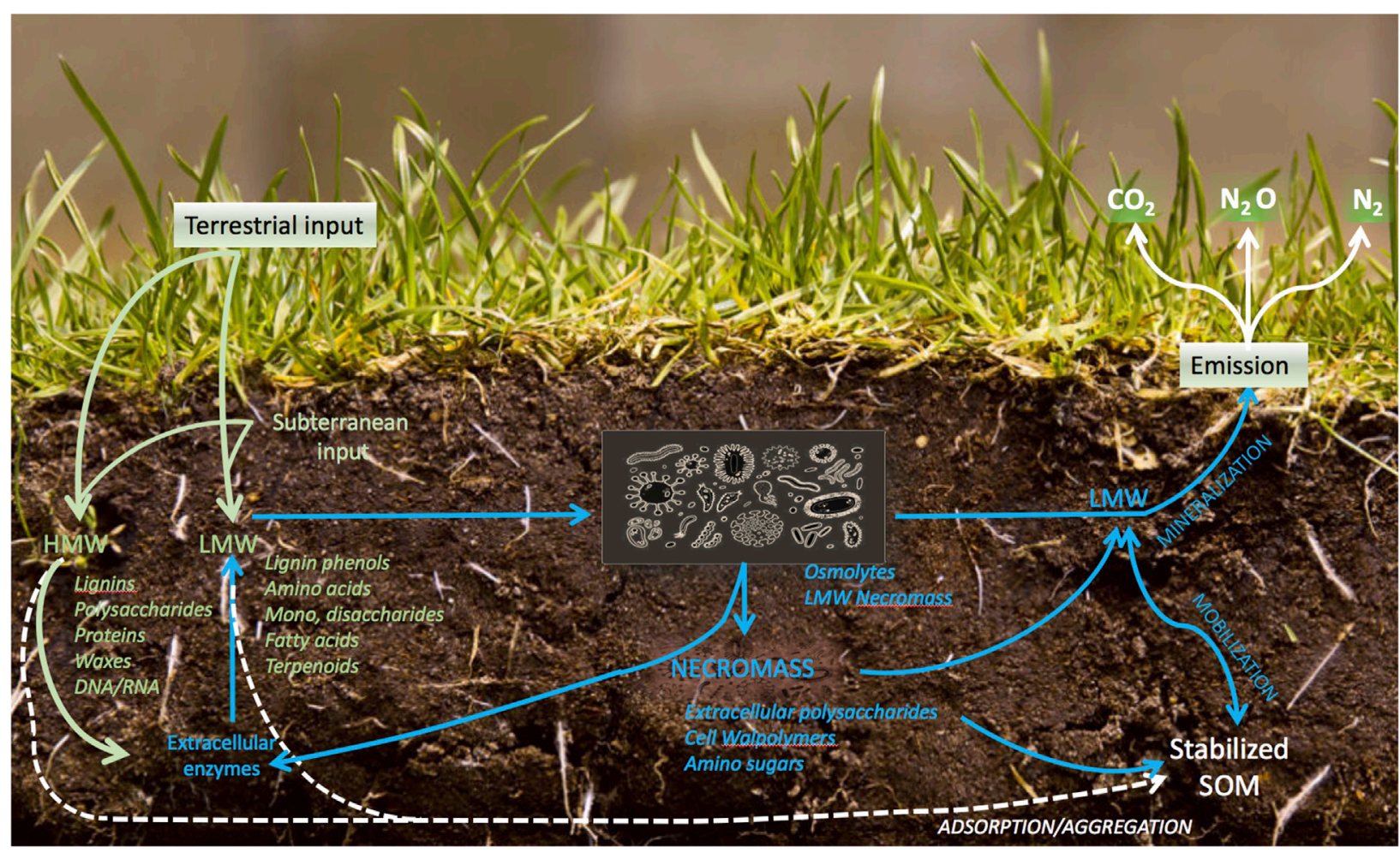

FIGURE 1 | Schematic diagram demonstrating pathways for stabilization of soil organic matter (SOM). LMW corresponds to Low Molecular Weight, and HMW to High Molecular Weight, respectively. The green arrows represent inputs, the blue arrows to microbial processes, and the white arrows to physicochemical processes. Redrawn from Overy et al. after modification.

and physical processes (Figure 1). Briefly, plant inputs in the form of aboveground and belowground litter and root exudates condition the physiology of the soil microbial communities. Soil microbes directly assimilate some low molecular weight (LMW) molecules and produce extracellular enzymes to degrade high molecular weight (HMW) plant inputs. The LMW can be 1) lost quickly by respiration, 2) stabilized by mineral interaction or 3) used by microbes to mobilize stabilized SOM compounds. Ultimately, most soil organic matter may originate from accumulation of microbial necromass.

The RT was intended to attract articles describing experimental research (in laboratory or field settings), involving extensive monitoring, or based on computer modelling. We particularly welcomed manuscripts that attempted to elucidate the complex physico-chemical and microbiological processes that control the storage of carbon in soils, as well as the environmental factors and land management strategies that influence them.

Of the seven articles that constitute this RT, five describe original research. Two of them deal with agricultural practices, whereas the other three focus on forests. Among the two agriculture-oriented ones, Lago et al. investigated the effects of agricultural management practices and earthworm additions on soil $\mathrm{C}$ losses, both in terms of $\mathrm{CO}_{2}$ emissions and dissolved organic carbon (DOC), in relation to the amount of bioavailable soil carbon. Their experimental results showed that earthworm additions led to significant increases in their abundance in all three management treatments, with the largest population sizes in the case of organic farming practices. However, no significant effect on soil $\mathrm{C}$ transformations were observed in response to these increases, and instead, legacy agricultural practices overrode macrofaunal control on $\mathrm{C}$ turnover. Consequently, more $\mathrm{C}$ was lost from the conventional treatments than from the organic farming practices (on average, $60 \%$ more $\mathrm{CO}_{2}$ and $53 \%$ more DOC) as a result of conventional treatments promoting microbially-mediated processes and hence, amplifying $\mathrm{C}$ mineralization versus $C$ stabilization. These findings provide clear evidence of how local adaptation (at farm level) toward a more environmentally friendly land management could represent a promising strategy to preserve soil organic matter or even increase soil $\mathrm{C}$ sequestration.

The second research article by Sulman et al. focuses on the distribution of soil carbon (SC) with depth, which, as previous research has shown, varies among ecosystems and land uses and is an important factor in calculating SC stocks and their vulnerabilities. The authors fit over 40,000 SC depth profiles, associated with a variety of land uses, both agricultural and forested, to an exponential decline relationship with depth to determine SC concentration at the top of the mineral soil, minimum SC concentration at depth, and the characteristic "length" of SC concentration decline with depth. Fitting these parameters allowed profile characteristics to be analyzed across a 
large and heterogeneous dataset. The results suggest that historically tilled soils had more gradual decreases of SC with depth, deeper SC profiles, lower SC concentrations at the top of the mineral soil, and lower total SC stocks integrated to $30 \mathrm{~cm}$. The extensive profile database allowed these results to be confirmed across different land cover types and spatial areas within the Continental United States.

Among the other three research articles, dealing strictly with forest soils, Merabtene et al. investigated the average amount of organic carbon stored in forest soils of Tessala Mount in Algeria and examined to what extent it was influenced by different plant formations along with geographical characteristics and soil physicochemical properties. These authors observed that the soil organic carbon stock in the region was positively correlated with coarse silt, elevation, and northern exposure, but negatively with calcium carbonates contents. The preliminary estimate of the forest soils organic carbon stock of Tessala Mount under current natural conditions indicates an alarming situation where the current $\mathrm{C}$ content is very low and close to the critical threshold, thus exposing this area to further and stronger degradation.

Pierson et al. assessed the response of soils to 20 years of detrital manipulations in a wet, temperate forest in Oregon (United States). Annual additions of low-quality (high C:N content) wood litter to the soil surface led to a greater positive effect on observed mean soil $\mathrm{C}$ concentration relative to additions of higher-quality (low C:N content) needle litter over the 20 years study period. Detrital input reduction treatments, including stopping live root activity and the aboveground removal of surface litter, led to relatively small, non-significant effects on soil $\mathrm{C}$ concentrations over the 20 years study period. Far greater negative effects on mean soil $\mathrm{C}$ concentrations were observed for the combined removal of both aboveground litter and belowground root activity, which led to an observed, yet also non-significant, $20 \%$ decline in soil C stocks. The substantial proportion of remaining soil $\mathrm{C}$ following these dramatic, longterm reductions in above- and belowground detrital inputs suggests that losses of $\mathrm{C}$ in these forest soils are not readily achieved over a few decades of reductions in detrital input and may require far greater periods of time or further perturbations to the environment. Further, the observed soil $\mathrm{C}$ responses to detrital manipulations support recent hypotheses regarding soil C stabilization, which emphasize litter quality and mineral stabilization as relevant controls over forest soil C.

The last of the research articles of the RT written by Ražauskaité et al. present measurements that provide comparative estimates of soil organic carbon in grassland and forest sites at steady state. The authors developed a new approach to interpret these values based on simulation of organic carbon turnover in soils that are accumulating carbon, and they used this approach to determine losses due to management operations associated with afforestation of grassland and deforestation/ reforestation of forest stands. Using measured data obtained at an experimental site in Scotland, the simulations of grassland afforestation suggested that accumulation of organic carbon under forest occurs mainly in the organic horizons, while the deeper sandy mineral soil horizons are likely to become depleted in organic carbon compared to grasslands. Simulations suggest that afforestation of grasslands would increase overall soil carbon stocks but may deplete the more stable carbon pools in the deeper mineral horizons of the podzols.

The last two articles of the RT provide reviews of specific aspects of the topic of the RT. In the first review article, Overy et al. describe the various "omics" platforms (metagenomics, metatranscriptomics, metaproteomics, and metabolomics), which use a systems biology approach of the complex array of processes involved in the transformation of carbon inputs into stable soil organic matter (see Figure 1). The authors argue that linking the data derived from these various platforms offers the opportunity to enhance our knowledge of structure and function of the microbial communities involved in soil carbon cycling and stabilization. They discuss the application, potential, and suitability of different "omics" approaches (independently and in combination). In this context, they highlight some of the biases associated with these approaches including limitations of the methods, experimental design, and soil sampling, as well as those associated with data analysis and interpretation.

The second review article, by Dynarski et al., focuses on the uncertainty associated with the permanence of newly sequestered soil carbon. They argue that this issue is of importance, regardless of the reason for which one attempts to increase the carbon content of soils. They review the evolution of the general understanding of soil $\mathrm{C}$ residence times and the language used to describe it in both scientific and policy sectors. They find that recent scientific findings concerning soil $\mathrm{C}$ residence times are not taken into account in policy discussions about soil C, and conversely, concerns by policy makers are not clearly addressed by scientific research. In that context, Dynarski et al. argue that soil C longevity can best be understood to result from a continuous movement and transformation of organic compounds throughout the soil matrix, and show that this definition is directly at odds with how soil C longevity is represented in current policies. They end their article by identifying priority areas for future research in order to answer key policymaker questions about soil $\mathrm{C}$ residence times, and to help develop new tools and benchmarks necessary to assess the efficacy of agricultural soil $\mathrm{C}$ sequestration efforts.

A message that emerges clearly from these two review articles is that the research on the storage and especially the long-term retention of organic matter in soils has become fundamentally interdisciplinary, out of necessity. From the broad perspective of policy development considered by Dynarski et al., it is obvious that sociological, political, and economical knowledge needs to be brought together to tackle the question of permanence of soil organic matter storage, which guarantees that soils are able to continue fulfilling their functions in the future. Yet even from a strictly scientific viewpoint, interdisciplinary research is essential (Baveye and Wander). Indeed, to assess how and to what extent part of the organic matter that is incorporated into soils and is not readily mineralized, eventually becomes stabilized, requires a holistic understanding of soil organic matter cycling. This includes not only the controls of the activity of soil microorganisms, but also the various physical and chemical processes influencing the "sequestration" of the end-products 
of their metabolism. In this context, Overy et al. considers that "omics" methods have been very useful, and should prove to be even more so in the future, to unravel the complex array of processes involved in the transformation of carbon inputs into stable soil organic matter. To exploit fully what these "omics" methods can tell us about the activity of soil microorganisms, soil organic matter specialists, who until not too long ago were (bio) geochemists by training, have to work hand in hand with microbiologists, as well as with specialists of other disciplines that also shed light on the environment in which these microorganisms live.

The mention of "omics" methods raises another point that is likely to attract attention and debate in years to come. It is the fact that these methods, as they are currently implemented, are macroscopic. Indeed, they all rely on the extraction of DNA or RNA from bulk soil samples, and therefore ignore the intricate details of the microscale heterogeneity of soils and the organic matter in them, and consequently also the distribution of microorganisms (Baveye, 2009; Baveye et al., 2018). Over the last 15 years, increasing numbers of researchers have recognized that in order to understand many soil processes, and to be able to predict their future evolution, especially under the unsteady conditions resulting from climate change, the traditional macroscopic approach does not work, and a microscopic perspective needs to be adopted instead (e.g., Pot et al., 2022; Smercina et al., 2021) hopefully leading in due course to novel types of macroscopic measurements (see discussion in Baveye et al., 2018). This conclusion has been particularly clear for soil processes involving microorganisms. Several key studies have demonstrated that to better understand the controls of the growth and activity of microorganisms, and in particular the mineralization of organic matter added to soils, observations have to be made at the scale at which they occur, i.e., with a resolution of a few microns, and it is anticipated that even much smaller resolutions than that will be needed for the understanding of the behaviour of viruses (e.g., bacteriophages) in soil environments. The progressive shift from the macroscale to the microscale to increase process understanding over the last few years has been rendered

\section{REFERENCES}

Amelung, W., Bossio, D., de Vries, W., Kögel-Knabner, I., Lehmann, J., Amundson, R., et al. (2020). Towards a Global-Scale Soil Climate Mitigation Strategy. Nat. Commun. 11, 5427. doi:10.1038/s41467-020-18887-7

Bandara, C. D., Schmidt, M., Davoudpour, Y., Stryhanyuk, H., Richnow, H. H., and Musat, N. (2021). Microbial Identification, High-Resolution Microscopy and Spectrometry of the Rhizosphere in its Native Spatial Context. Front. Plant Sci. 12, 668929. doi:10.3389/fpls.2021.668929

Baveye, P. C. (2009). To Sequence or Not to Sequence the Whole-Soil Metagenome? Nat. Rev. Microbiol. 7 (10), 756. doi:10.1038/nrmicro2119-c2

Baveye, P. C. (2021). Bypass and Hyperbole in Soil Research: Worrisome Practices Critically Reviewed through Examples. Eur. J. Soil Sci. 72, 1-20. doi:10.1111/ejss.12941

Baveye, P. C., Otten, W., Kravchenko, A., Balseiro-Romero, M., Beckers, É., Chalhoub, M., et al. (2018). Emergent Properties of Microbial Activity in Heterogeneous Soil Microenvironments: Different Research Approaches Are possible by tremendous technological advances, such as the advent of dedicated table-top X-ray computed tomography scanners, and the development of various synchrotron-based techniques (such $\mu \mathrm{XRF}$ or NEXAFS) as well as NanoSIMS. Experimental research in this field has been very active and is currently undergoing a major expansion around the world, in particular in work that combines several different observation techniques (e.g., Schluiter et al., 2019; Bandara et al., 2021; Gerke et al., 2021). In the future, the detailed information obtained by these methods needs to be integrated with large-scale observations to improve soil organic matter management at the landscape level.

As the seven articles of this RT, and the above discussion indicate, many questions remain unanswered concerning the long-term stabilization of organic matter in soils. There is a widely acknowledged consensus among researchers, regardless of their philosophical orientations or past experience, that this long-term retention of organic matter in soils, and its effect on the resilience of soil architecture (e.g., Vogel et al., 2021), are essential to guarantee that soils will be able, in spite of climate change, to continue fulfilling the key functions on which humanity depends (Baveye et al.). As the latest IPCC report points out clearly, we only have very limited time to gather the required knowledge. As daunting as the challenge may be, we have to make progress rapidly and learn while we apply most promising soil carbon sequestration practices to confront head on the unprecedented urgency we face.

\section{AUTHOR CONTRIBUTIONS}

All authors listed have made a substantial, direct, and intellectual contribution to the work and approved it for publication.

\section{ACKNOWLEDGMENTS}

We would like to express our sincere gratitude to the various reviewers who very generously volunteered their time to help the authors improve their texts.

Slowly Converging, yet Major Challenges Remain. Front. Microbiol. 9, 1929. doi:10.3389/fmicb.2018.01929

Berthelin, J., Laba, M., Lemaire, G., Powlson, D., Tessier, D., Wander, M., et al. (2022). Soil Carbon Sequestration for Climate Change Mitigation: Mineralization Kinetics of Organic Inputs as an Overlooked Limitation. Eur. J. Soil Sci. 73, e13221. doi:10.1111/ejss.13221

Ferdush, J., and Paul, V. (2021). A Review on the Possible Factors Influencing Soil Inorganic Carbon under Elevated CO2. Catena 204, 105434. doi:10.1016/j. catena.2021.105434

Gao, D., Joseph, J., Werner, R. A., Brunner, I., Zürcher, A., Hug, C., et al. (2021). Drought Alters the Carbon Footprint of Trees in Soils-Tracking the Spatiotemporal Fate of 13 C-labelled Assimilates in the Soil of an Old-growth pine forest. Glob. Change Biol. 27, 2491-2506. doi:10.1111/gcb.15557

Gerke, K. M., Korostilev, E. V., Romanenko, K. A., and Karsanina, M. V. (2021). Going Submicron in the Precise Analysis of Soil Structure: A FIB-SEM Imaging Study at Nanoscale. Geoderma 383, 114739. doi:10.1016/j.geoderma.2020. 114739 
Guttières, R., Nunan, N., Raynaud, X., Lacroix, G., Barot, S., Barré, P., et al. (2021). Temperature and Soil Management Effects on Carbon Fluxes and Priming Effect Intensity. Soil Biol. Biochem. 153, 108103. doi:10.1016/j.soilbio.2020. 108103

Kaštovská, E., Cardenas-Hernandez, J., and Kuzyakov, Y. (2021). Priming Effects in the Rhizosphere and Root Detritusphere of Two Wet-Grassland Graminoids. Plant and Soil. in press. doi:10.1007/s11104-021-05191-6

Laub, M., Ali, R. S., Demyan, M. S., Nkwain, Y. F., Poll, C., Högy, P., et al. (2021). Modeling Temperature Sensitivity of Soil Organic Matter Decomposition: Splitting the Pools. Soil Biol. Biochem. 153, 108108. doi:10.1016/j.soilbio.2020.108108

Moinet, G., Midwood, A., Hunt, J., RumpelMillard, C. P., Millard, P., and Chabbi, A. (2019). Grassland Management Influences the Response of Soil Respiration to Drought. Agronomy 9 (3), 124. doi:10.3390/agronomy9030124

Moinet, G. Y. K., Moinet, M., Hunt, J. E., Rumpel, C., Chabbi, A., and Millard, P. (2020). Temperature Sensitivity of Decomposition Decreases with Increasing Soil Organic Matter Stability. Sci. Total Environ. 704, 135460. doi:10.1016/j. scitotenv.2019.135460

Pot, V., Portell, X., Otten, W., Garnier, P., Monga, O., and Baveye, P. C. (2022). Accounting for Soil Architecture and Microbial Dynamics in Microscale Models: Current Practices in Soil Science and the Path Ahead. Eur. J. Soil Sci. 73 (1), 213142. doi:10.1111/ejss.13142

Raza, S., Zamanian, K., Ullah, S., Kuzyakov, Y., Virto, I., and Zhou, J. (2021). Inorganic Carbon Losses by Soil Acidification Jeopardize Global Efforts on Carbon Sequestration and Climate Change Mitigation. J. Clean. Prod. 315, 128036. doi:10.1016/j.jclepro.2021.128036

Rumpel, C., Amiraslani, F., Koutika, L.-S., Smith, P., Whitehead, D., and Wollenberg, E. (2018). Put More Carbon in Soils to Meet Paris Climate Pledges. Nature 564, 32-34. doi:10.1038/d41586-018-07587-4

Rumpel, C., and Chabbi, A. (2021). Managing Soil Organic Carbon for Mitigating Climate Change and Increasing Food Security. Agronomy 11 (8), 1553. doi:10. 3390/agronomy11081553
Schlüter, S., Eickhorst, T., and Mueller, C. W. (2019). Correlative Imaging Reveals Holistic View of Soil Microenvironments. Environ. Sci. Technol. 53, 829-837. doi:10.1021/acs.est.8b05245

Smercina, D. N., Bailey, V. L., and Hofmockel, K. S. (2021). Micro on a Macroscale: Relating Microbial-Scale Soil Processes to Global Ecosystem Function. FEMS Microbiol. Ecol. 97 (7), fiab091. doi:10.1093/femsec/fiab091

Thilakarathna, S. K., and Hernandez-Ramirez, G. (2021). How Does Management Legacy, Nitrogen Addition, and Nitrification Inhibition Affect Soil Organic Matter Priming and Nitrous Oxide Production? J. Environ. Qual. 50 (1), 78-93. doi:10.1002/jeq2.20168

Vogel, H.-J., Balseiro-Romero, M., Kravchenko, A., Otten, W., Pot, V., Schlüter, S., et al. (2021). A Holistic Perspective on Soil Architecture Is Needed as a Key to Soil Functions. Eur. J. Soil Sci. 1, 14. doi:10.1111/ejss.13152

Conflict of Interest: The authors declare that the research was conducted in the absence of any commercial or financial relationships that could be construed as a potential conflict of interest.

Publisher's Note: All claims expressed in this article are solely those of the authors and do not necessarily represent those of their affiliated organizations, or those of the publisher, the editors, and the reviewers. Any product that may be evaluated in this article, or claim that may be made by its manufacturer, is not guaranteed or endorsed by the publisher.

Copyright (C) 2022 Chabbi, Rumpel, Hagedorn, Schrumpf and Baveye. This is an open-access article distributed under the terms of the Creative Commons Attribution License (CC BY). The use, distribution or reproduction in other forums is permitted, provided the original author(s) and the copyright owner(s) are credited and that the original publication in this journal is cited, in accordance with accepted academic practice. No use, distribution or reproduction is permitted which does not comply with these terms. 